\title{
LEPRA, LAZARETO Y LEPROSOS: MEMORIAS DE UNA ENFERMEDAD OLVIDADA'
}

Dayana Lucía Lizcano Herrera Universidad Santo Tomás - Bucaramanga

\section{Resumell:}

Desde su aparición en el periodo colonial, en el territorio que hoy conforma Colombia, la lepra fue una enfermedad que generó un fuerte impacto social y político, conllevando a la implementación de políticas centralizadas de segregación, ostracismo y coerción de los leprosos; constituyéndose los lazaretos a partir de 1905 en instituciones de aislamiento que posteriormente pretendieron transformarse en instituciones medico sanitarias, conversión que en la práctica no logró materializarse, aún así en 1961 los lazaretos fueron oficialmente abolidos. Este artículo, producto de investigación personal, presenta la política del Estado frente a la lepra y los leprosos como problema para la higiene, la salud pública y la sana convivencia; a su vez se estudia la emergencia y decadencia de los lazaretos colombianos.

\section{Palabras clave:}

Lepra, Lazareto, Leproso.

\section{LEPROSY, LAZARUS AND LEPERS: MEMORIES OF A FORGETTABLE DISEASE}

\section{Abstract}

Leprosy, since its starting in the Colonial period in the land that today is named Colombia, was a disease that created a strong social and political impact leading to implementation of segregation government policies, ostracism and lepers coercion, becoming the Lazarus since 1905 in isolating institutions that pretended to be medical institutions lately; such change could not come true, even the Lazarus were officially abolished in 1961.

\section{Key words:}

Leprosy, the Lazarus, lepers.

1 El presente artículo hace parte de una investigación histórica sobre la política del Estado frente a la lepra y los leprosos, y la comprobación de su materialización a través del estudio interno del lazareto de Contratación; En el proyecto denominado: “ Lepra, Lazareto y Leprosos: Memorias de una enfermedad olvidada".Escuela de Historia de la Universidad Industrial de Santander. (UIS). 2005

2 Historiadora y Magíster en Historia de la Universidad Industrial de Santander, Docente del Departamentos de Humanidades de la Universidad Santo Tomás Seccional Bucaramanga y de las Unidades Tecnológicas de Santander. Vinculado al Grupo de Investigaciones Históricas sobre el Estado-Nacional Colombiano, registrado en COLCIENCIAS en categoría B. mhuisdaliz@hotmail.com 


\section{Introducción}

Para muchas personas en Colombia hablar de lepra en los albores del siglo XXI, es evocar la historia de las poblaciones que subsistieron en este territorio bajo condiciones materiales bastante precarias, otras personas sólo saben de la enfermedad por las menciones que en la Biblia se hacen de ella, cuando se asimila su contagio al pecado. En la actualidad la lepra parece ser una enfermedad de otros tiempos, de aquellos en que los individuos vivían en estado de mayor pobreza, insalubridad e incivilidad. Agua de Dios y Contratación en la concepción de la población, en especial de la más joven, son exclusivamente municipios, el primero ubicado en Cundinamarca y el segundo en Santander, pero su catalogación e historia como Lazaretos o Leprocomios es desconocida.

En consecuencia, la investigación se hace con la finalidad de rememorar a aquellos que por infortunio enfermaron de lepra y fueron segregados, exiliados, cohibidos y humillados por padecer una enfermedad que los deformó corporalmente y los incapacitó, y para recordar a la sociedad que esta enfermedad continua manifiesta en el panorama nacional, durante el año 2010 el Sanatorio de Contratación reportó cinco casos de personas que arribaron allí para recibir tratamiento y el auxilio pecuniario que el Estado sigue dando a los dolientes.

La primera parte del trabajo, es un recorrido histórico de la lepra y de los lugares instaurados para la confinación de los leprosos, se inicia desde la aparición de la enfermedad en el territorio que hoy conforma Colombia hasta la eliminación de los lazaretos en 1961. En la segunda parte del estudio, que se publicará en próximo número, muestra cómo se estableció la conformación y funcionamiento del lazareto de Contratación para luego observar hasta qué punto la constitución institucional de los lazaretos logró cum- plirse. Por consiguiente, se identificaron los establecimientos asistenciales, médicos, administrativos y religiosos que laboraron al servicio del lazareto y el papel de la Comunidad Salesiana, como agente representativo en su desarrollo y operatividad. De igual forma, se realizó un pequeño acercamiento a los enfermos de lepra que habitaron en el lazareto de Contratación, para construir su caracterización e identificar sus percepciones respecto a la lepra, el lazareto y a los funcionarios que los asistieron

\section{Metodología}

Del cúmulo de enfermedades que la hueste de conquistadores trajo a este país, la lepra por su capacidad de deteriorar corporalmente a quienes la padecían y por lo inexplicable de su contagio, fue de las que mayor terror infundió en la población. De ahí, el interés de las autoridades gubernamentales y de la sociedad en general por adecuar los espacios destinados a la proscripción de los leprosos. Aunque los índices de mortalidad de la lepra son mínimos, fue la única enfermedad para la que se decretó una legislación especial y se invirtió gran parte del presupuesto nacional destinado a la salud pública. Razones por las que creería que la Historia, ciencia encargada de construir los hechos acontecidos, se hubiese inclinado a escribir y a contar a las nuevas generaciones todos los acontecimientos que se propiciaron para contener la lepra. Sin embargo, para el momento en que se realizó esta investigación, eran escasos los estudios historiográficos sobre este tema, en especial investigaciones que intentaran comprobar el cumplimiento de las disposiciones estatales mediante el estudio de su aplicación en un lazareto, para este caso el lazareto de Contratación.

En algunas ocasiones la inexistencia de fuentes de información distintas a la documentación oficial, puede limitar la labor del historiador porque construye acaeci- 
mientos que sólo representan el ideal o el deber ser, pero está en la capacidad que tiene el profesional de la historia de discriminar entre lo falso y lo verdadero, poder mostrar con objetividad un acercamiento de lo acontecido. No obstante, para la realización de esta investigación, afortunadamente, se contó con los documentos oficiales emitidos por el Gobierno Nacional y por la autoridad interna del lazareto de Contratación, al igual que con cartas, memorias, diarios y libros que escribieron algunos enfermos y el personal religioso que los asistió durante el siglo $X X$ y que habitaron dentro de esta institución de aislamiento. Información que permitió determinar la consecución de las políticas dictadas para menguar los alcances de la lepra a través de la segregación y sometimiento de los leprosos; a la par que permitió conocer las percepciones de estas personas referente al trato dado por la población exenta de la enfermedad que convivió junto a ellos. El desconocimiento de estos últimos factores permitió a la investigación adquirir un alto grado de originalidad, confiabilidad y aportar a la historiografía.

Para efectuar una investigación que correlacionara el deber ser con el ser y que lo hiciera mediante el estudio de un lazareto desestimado por la historiografía al no haber alcanzado oficialmente la importancia que llegó a tener el lazareto de Agua de Dios, se acudió al método heurístico y hermenéutico. El primero para localizar las fuentes de información básicas del historiador, es decir, las fuentes primarias, aquellas dadas en el tiempo y el espacio que se estudia; y el segundo para hacer una crítica y contrastación de la información recolectada y acercarse a una explicación fidedigna del hecho histórico.

En la obtención de la información interna del antiguo lazareto de Contratación, fue necesario trasladarse y permanecer por extensos periodos en este munici- pio, debiéndose organizar la devastada, fragmentada y escasa información que se encuentra al respecto, ubicada en el archivo del hospital San Juan Bosco; y entrevistar a los enfermos que vivieron bajo el régimen del lazareto. El resto de la información con la que se realizó la investigación se tomó del Archivo General del Departamento de Santander. La organización de toda la información y la redacción del texto final, al igual que de este artículo, se hizo de manera cronológica y narrativa.

\section{La lepra y las políticas de Estado para contener su propagación}

Si bien, es difícil determinar con exactitud el origen histórico de la lepra por la carencia de conocimientos adecuados para diagnosticar y registrar las enfermedades en la antigüedad y por los exiguos vestigios que la enfermedad deja en esqueletos y en los cuerpos momificados, por haberse encontrado los casos más antiguos de lepra en momias egipcias que datan del siglo II a.c, se situó el origen de la este padecimiento en Egipto. Desde allí fue llevada a Asia y Europa por los comerciantes, guerreros e inmigrantes, para luego desembarcar en las Indias Occidentales, hoy América, con las huestes de conquistadores europeos en el siglo $\mathrm{XVI}$, en donde el Nuevo Reino de Granada (Colombia) no fue ajeno a su penetración, se propagó al igual que las enfermedades contagiosas por la rutas comerciales, especialmente a través de los valles y cuencas hidrográficas vinculadas con el rio Magdalena. La historiografía reportó entre los primeros leprosos conocidos al conquistador español Don Gonzalo Jiménez de Quesada, a quien sus congéneres optaron por enviarlo de regreso a su país y esconder su padecimiento para evitar el escarnio y señalamiento público, de igual manera se comprobó que la falta de defensas inmunológicas de los nativos los hizo más susceptibles al contagio. 
Dando continuidad a las ancestrales prácticas de segregación que empleaban los israelitas para esconder al leproso, a quien llamaban impuro por sufrir una enfermedad reflejo del pecado, en Nueva Granada desde la aparición de la lepra en el periodo colonial se adoptó una política centralizada de aislamiento en los hospitales de San Lázaro o lazaretos, lugares destinados a la reclusión de los enfermos pobres porque a los de mejor condición socioeconómica se les permitió habitar en espacios lejanos de los grandes poblados, en donde no representaran un peligro para la sana convivencia.

A comienzo del siglo XVII, se erigió un hospital de San Lázaro ubicado en el centro de Cartagena de Indias, pero el temor generalizado en los habitantes a convivir cerca de los enfermos conllevó a trasladarlo hacía las zonas periféricas, siendo finalmente establecido en la isla de Tierrabomba, en el sitio de Caño de Loro, en donde permaneció hasta la primera mitad del siglo $X X$ cuando fue definitivamente eliminado. La vasta distancia de este centro con el resto del país y la insuficiencia y precariedad de las vías de comunicación hacían casi imposible la movilización de los enfermos procedentes de regiones distantes a Cartagena, travesía en la que en ocasiones fenecían antes de llegar a su destino final.

La dificultad para recluir a todos los leprosos en el lazareto de Caño de Loro y lo pernicioso que resultaba para el comercio la proliferación de la lepra y la permanencia de los convalecientes en lugares fuera del control de las autoridades, generó que integrantes de las familias más prestantes, residentes en localidades importantes por la producción o intercambio de mercancías, solicitaran al virreinato la instauración de otros lazaretos, requerimiento rechazado asiduamente por la inexistencia de recursos. Aspecto que no fue impedimento para que los habitantes de la Provincia del Socorro en 1784 acondicionaran una casa a las afueras del poblado, en el sitio denominado Regadillo, para recluir a los lazarinos, más la estreches de la misma y el aumento vertiginoso de enfermos, obligó a los Socórranos a reubicar a sus paisanos leprosos en el Curo, al margen del río Suárez, terreno más amplio y confortable.

No obstante, las inundaciones, las epidemias, el clima cálido y malsano pronto propiciaron la emigración de los enfermos a otro lugar, llegando a establecerse en Contratación, un pequeño valle de la cordillera de los Yariguies irrigado por las quebradas Agua Fría y la Macaligua. Contratación, o "Contrata" como se le conocía por el comercio de quina que allí se realizaba, era un sitio recóndito, de difícil acceso y de condiciones ambientales húmedas con corrientes frías que propiciaban el desarrollo progresivo de la enfermedad, pero con abundantes fuentes hídricas y terrenos fértiles (Pérez, 2004: p. 79).

Superados los avatares de la lucha independentista, el nuevo Gobierno Republicano en 1833 nacionalizó y reorganizó los lazaretos de origen colonial, Caño de Loro y Contratación, a la par que expresó su intención de erigir otros, pero nuevamente las limitaciones fiscales y las reformas político administrativas que se presentaban por el nuevo orden, imposibilitaron la materialización de tan laudable proyecto, dado que los enfermos que eran remitos a los lazaretos vivían en hacinamiento, los demás deambulaban sometiéndose a los vejámenes de los indolentes o escondidos para evitar esto.

Cuando el proyecto del liberalismo radical se concretó con la formación de Estados Soberanos vinculados a través de un modelo federal, fueron precisamente los anteriores factores los que llevaron a los leprosos a conformar otro lazareto en el Estado de Cundinamarca en 1867. Un gran número de enfermos se concentró 
voluntariamente en Agua de Dios, poblado cerca a las aguas termales de Tocaima, preferidas por los dolientes porque suavizaban los dolores físicos que la lepra les ocasionaba. Acontecimiento que fue aprovechado por el Gobierno para ascender a tres los establecimientos destinados al aislamiento de los leprosos en el país, lugares desde los cuales se concentraron las políticas gubernamentales que constantemente fueron apareciendo para evitar la propagación de una enfermedad sobre la que pesó más el estigma y los prejuicios que sus verdaderos alcances. Si bien, la enfermedad era infectocontagiosa no todas las personas eran susceptibles a contraerla y sus índices de mortalidad eran mínimos, ya que los leprosos no fenecían directamente de la enfermedad sino a causa de las complicaciones que de ésta se derivaban.

El desconocimiento de la causalidad y modo de transmisión de la lepra, la gravedad de sus manifestaciones y la ausencia de un concepto unívoco que la definiera, generó que la enfermedad fuera en un comienzo asumida como un castigo enviado por Dios por acometer acciones pecaminosas que corrompían el alma, en especial por la relación que se estableció entre la lepra y las enfermedades venéreas al creerse que ella era el resultado de una sífilis en su estado más avanzado; adelantado el periodo colonial su contagio también se relacionó el consumo de ciertos alimentos o a influencias climatológicas.

Durante la segunda mitad del siglo XIX, ante la inexistencia de una explicación convincente sobre la causa de esa dolencia, la naciente comunidad médica postuló diversas teorías, entre las que estaban las miasmáticas, dietéticas, higiénicas, contagiosas, electromagnéticas y hereditarias. Siendo esta última la que predominó hasta 1874 cuando el científico noruego G. A. Hansen descubre el microorganismo causante de la enferme- dad, conocido como MYCOBACTERIUM LEPRAE o bacilo de Hansen. La aceptación de la teoría que relacionaba la causa de la lepra con un agente bacteriológico especifico permitió pasar a relacionar la enfermedad con la insalubridad, pobreza e incivilidad propias de las naciones con menor grado de desarrollo; a la par que despertó entre la comunidad médica mundial un fervoroso optimismo, puesto que se desestimaba así la creencia de la incurabilidad de la enfermedad y por el contrario se concebía la idea del descubrimiento de un tratamiento médico específico para erradicarla.

La comunidad médica colombiana a pesar de sus limitadas condiciones técnicas se lanzó a la búsqueda de un método terapéutico basado en doctrinas científicas que contuviese la enfermedad y que le otorgara reconocimiento mundial, ya que afanosamente deseaban adquirir prestigio nacional y con mayor ímpetu internacional. Sin desestimar el interés por el estudio de la lepra que tuvieron algunos médicos colombianos como Juan de Dios Carrasquilla, el desconocimiento del modo en que el vacilo se transmitía, la falta de recursos financieros y tecnológicos para efectuar investigaciones científicas, el poco compromiso de algunos médicos que continuaban viendo a la lepra con estupor y recelo al no aceptar tener contacto con los leprosos y la incapacidad estatal de ejecutar medidas profilácticas, provocaron que los intentos por obtener un tratamiento efectivo para su erradicación fueran fallidos, obligando al Estado a continuar responsabilizarse de su control a través de políticas represivas, crueles y poco efectivas.

Una de las alternativas de las autoridades gubernamentales para soterrar la incapacidad de medicalizar los mecanismos para enfrentar a la lepra y menguar sus consecuencias, fue centralizar el control de la enfermedad y a sus dolientes mediante la abolición de los lazaretos 
existentes, para en su remplazo construir un "Gran Lazareto Nacional" en la isla de Coiba, ubicada en el Pacífico colombiano (Rabagliati, 1899: p. 5). Propósito respaldado por un gran porcentaje de médicos y religiosos salesianos, quienes habían llegado al país en 1890 y desde entonces habían inclinado su labor misional al servicio de los leprosos, pero rechazado rotundamente por los enfermos y por varios miembros de la élite dirigente $y$ médica, al considerar que esto acarreaba cuantiosos gastos para las empobrecidas arcas del país y porque su planeación se basó más en la intención de alejar de la vista pública a los temidos leprosos, empleando prácticas represivas y coercitivas que atentaban contra la integridad de los enfermos y no a través de una política de higiene tendiente a controlar la enfermedad con acciones médicas, asistenciales y salubres.

Sin embargo, el proyecto del "Gran Lazareto Nacional" se desecho después del encuentro efectuado en el exterior entre Hansen y el padre Evasio Rabagliati, quien era uno de los primeros salesianos en llegar a Colombia y el encargado de dirigir la misión de la orden destinada al servicio de los enfermos de lepra. Para el científico noruego la aglomeración de todos los enfermos en un sólo punto viciaba y corrompía la atmósfera de ese lugar, imposibilitaba la permanencia del personal médico y asistencial, puesto que los hacia más vulnerables a contagiarse, además era inmanejable la permanencia de los dolientes en un mismo recinto, agudizando por consiguiente el mutuo sufrimiento (Rabagliati, 1899: p. 10).

A su regresó al país Rabagliati reorientó su discurso hacía la construcción de lazaretos departamentales que debían ser establecidos bajo condiciones salubres para que los enfermos vivieran sana y cómodamente. Aunque la conformación de lazaretos regionales fue una aspiración manifiesta de algunos gobiernos locales desde el período colonial, la oposición de las administraciones centrales, la resistencia de la población sana a convivir cerca de los enfermos y los numerosos gastos que ello demandaba no habían hecho posible la realización de este objetivo; como ya se mencionó los lazaretos se conformaron por la concentración de los enfermos en un mismo espacio y por la colaboración poco desinteresada de algunas personas de mejor condición socioeconómica, quienes voluntariamente daban donativos creyendo que al alejar a los leprosos la enfermedad desaparecía. En consecuencia, las recomendaciones dadas por Hansen al religioso, nuevamente quedaron en retórica, su materialización no logró concretarse.

Los anteriores inconvenientes, la necesidad de evitar la proliferación de la enfermedad y de alejar a los enfermos por el temor que causaba la descomposición de sus cuerpos conllevó al Gobierno a dictar la Ley 104 de 1890, en la que se de declaraba la proscripción de los leprosos en los lazaretos como una "medida de urgente necesidad pública", se reafirmaba la concepción de la lepra como un "problema" que amenazaba el bien público, el orden y la tranquilidad de la población (Ley 104, diciembre 20-1890). No obstante, fue en 1905 cuando realmente se emprendió una campaña costosa, cruel y poco efectiva contra la lepra, alcanzando las políticas para controlarla el máximo de su rigidez.

Las nuevas medidas intensificaron el asecho de todos los enfermos sin distinción y la obligatoriedad de ser trasladados a los lazaretos (Ley 14, mayo 3-1907). Se ordenó a todo colombiano denunciar ante las autoridades a las personas sospechosas de poseer esta enfermedad, eximiéndose a los médicos del secreto profesional en el caso de lepra (Decreto $N^{\circ} 14$, enero 26-1905). Asimismo, se ordenó a los alcaldes y a los policías retener y llevar por la fuerza a los leprosos hasta los lazaretos, en donde los enfermos quedaban 
condenados a permanecer a perpetuidad y a perder sus derechos civiles y políticos, ya que se les decretaba la muerte social.

Los lazaretos al igual que las instituciones carcelarias fueron custodiados por guarniciones militares o policivas en ocasiones cercadas con alambres de púas denominado "cordón sanitario", el cual fue instaurado como un "dispositivo disciplinario" (Foucault, 1976: p, 25) ${ }^{3}$ para mantener a sus residentes vigilados $y$ controlados, para procurar la docilidad y obediencia de los internos, y para prevenir toda forma de inconformidad que se manifestara en levantamientos, insurrecciones o la fuga de los enfermos, falta que se castigaba drásticamente con el encarcelamiento, privación de los privilegios y la retención de la poca ayuda monetaria que el Gobierno les suministraba para subsistir, denominada "Ración" (Resolución No 104, agosto 5-1910). Con esas medidas y al desviarse todos los caminos públicos que comunicaban a los lazaretos también se buscó alejar y hacer más difícil el acceso de los familiares, los comerciantes o los curiosos (Decreto $\mathrm{N}^{\circ}$ 377, marzo 26-1907).

Hasta entonces los lazaretos se caracterizaban por ser lugares en donde los enfermos de lepra convivían libremente con las personas exentas de la dolencia, las cuales no se regían por la legislación especial dictada para los leprosos, puesto que al finalizar el siglo XIX, el incremento del número de ellos provocó el ascenso político-administrativo de estos lugares a distritos municipales, aspecto que significó la separación de la autoridad hospitalaria del administrador del lazareto de la autoridad del alcalde; el primero gobernaba exclusivamente a los enfermos y el segundo a las personas sanas que residían en cada uno de los tres lazaretos.

\footnotetext{
3 Michel Foucault Vigilar y Castigar: Nacimiento de la Prisión, define los Dispositivos Disciplinarios como los mecanismos que permiten imponer un orden, controlando y ordenando los cuerpos para que permanezcan quietos, dóciles e útiles por medio de la sujeción constate de sus fuerzas.
}

No obstante, la reglamentación que trajo consigo la nueva centuria buscó modificar las múltiples problemáticas generadas por esa dualidad gubernamental, por consiguiente se abolió el rango de municipalidad otorgadas a las poblaciones-lazareto y se restringió el número de individuos que podían vivir junto a los enfermos, tan sólo se autorizó a aquellos que tuvieran algún vinculo conyugal o estuvieran dentro del primer grado de parentesco civil de consanguinidad con los convalecientes, o algún empleado o sirviente cuando demostrara ser útil y necesario para un enfermo no hospitalizado. Estos individuos debieron someterse a la misma reglamentación de los leprosos, cuyo desacato acarreó castigos como multas, la expulsión de los lazaretos o la privación de la libertad en un centro carcelario ubicado dentro de éste o en el municipio más cercano, según la magnitud del hecho (Ley 32, octubre 29-1918). Para 1933, en procura de controlar nuevamente la permanencia injustificada de personas sanas en los lazaretos se les obligó a portar una cédula de identificación personal y se reiteraron las intenciones del Gobierno Nacional de descongestionar los lazaretos mediante la expulsión o restricción de estos sujetos. Fue así, como no se desaprovecharon las oportunidades para sancionarlos y si era posible expulsarlos.

De igual forma, los individuos exentos de lepra para poder abandonar momentáneamente los lazaretos necesitaban de un permiso que el administrador otorgaba por tiempo restringido y someterse a los procesos de desinfección impuestos a las personas y objetos que deseaban salir de los perímetros que constituían los lazaretos, hecho que reflejaba el temor al contagio y el estupor que provocaba la enfermedad y todo lo que procediera de esos centros; es por esta misma razón que dentro de los poblados se prohibió la circulación de la moneda nacional, siendo remplazado por una moneda especial 
denominada "coscoja" (Decreto No 903, octubre 13-1910).

Los enfermos de lepra al arribar a los lazaretos eran examinados por médicos para corroborar la posesión de la enfermedad y poder decretarles la "alta", denominación dada al proceso que certificaba el contagio y la obligación de habitar en esos lugares hasta el momento de su deceso, es decir, la alta condenaba al ostracismo del que no había posibilidad de eludir sin transgredir la normatividad. Durante el momento de ingreso se les abría la historia clínica, en donde, además del estado del salud del leproso se consignaban datos personales, familiares y el organismo que los había remitido, anexándose una fotografía tomada en ese instante; a continuación se les entregaba la boleta de ración y se les ubicaba dentro del lazareto. Si el enfermo ya vivía o tenía familiares residiendo en ese lugar, el Jefe de alojamiento, encargado de ubicarlos, les permitía residir con ellos para compartieran su penuria.

Si el estado de salud del enfermo era grave, se recluía en los hospitales de acuerdo a su género y se negaba a los familiares sanos que lo acompañaban, la posibilidad de quedarse en el lazareto. Lo mismo sucedía con los menores que eran enfermos y cuyos padres no lo eran (Resolución N ${ }^{\circ}$ 29, marzo 14/1921). Los demás enfermos eran ubicados en viviendas o habitaciones de propiedad del Estado o alquiladas por el mismo, incluso los enfermos de mejor condición económica podían comprar las viviendas a los particulares. En 1919 el Gobierno Nacional autorizó a los administradores de los lazaretos otorgar permisos a los enfermos para que construyeran casas, cuyos perímetros eran previamente delimitados, las cuales podía el leproso ocuparlas de por vida y heredarlas a sus familiares enfermos, de lo contrario debían venderlas al Gobierno o a otros convalecientes (Resolución No 113, diciembre 31-1919). Estas fueron las edificaciones que se comercializaron más adelante cuando los lazaretos ya estaban superpoblados.

El incremento acelerado de los leprosos llevó a las autoridades nacionales y de los lazaretos a buscar un mejor aprovechamiento del espacio a través de la ubicación de un mayor número de enfermos dentro de una misma edificación y la no concesión de alojamiento en casas particulares mientras en los hospitales o asilos existiera espacio disponible (Resolución $\mathrm{N}^{\circ} 26$, mayo 15-1925). Quienes se resistían a estas disposiciones eran sancionados con la restricción de su ración y no tenían derecho a exigir alojamiento por cuenta del Gobierno (Resolución $N^{\circ}$ 23, febrero 9-1932).

Las viviendas o habitaciones concedidas eran temporales y sujetas a cualquier modificación o disposición que las autoridades creyeran convenientes. Sin embargo, hubo enfermos que se negaban a devolverlas ocasionado gastos desmesurados, ante todo cuando las edificaciones eran alquiladas. Fue así, como se hizo necesario reglamentar esa práctica, ordenándose a los enfermos de lepra que se les hubiera suministrado alojamiento gratis, a ocuparlas y desocuparlas en las fechas que determinaban las oficinas o entidades oficiales, porque su incumplimiento ocasionaba el desalojo forzado, del cual debía encargarse el corregidor del lazareto junto con la policía interna (Resolución No 38, Abril 28-1931). Las causas más comunes de desalojo fueron entre otras, la necesidad de entregar a los particulares el predio arrendado, problemas de orden público que presentaban los enfermos, desacato o incumplimiento a las normas establecidas, o cuando era ineludible la hospitalización de la persona a quien se le había concedido la vivienda.

Pese a la reglamentación determinada y a las constantes prohibiciones del Gobierno Nacional y de las autoridades internas de los lazaretos, los enfermos ingresaron a 
estos lugares con sus familias y se ubicaban con ellos muchas veces en alojamientos del o costeados por el Estado. Siendo esto una de las causas que motivaron al Gobierno a restringir incesantemente la permanencia de individuos exentos de lepra, personas que no sólo abarcaban espacios que podían ser ocupados por los convalecientes, en algunas ocasiones también vivían de sus raciones, pero sobre todo eran personas que por estar en contacto directo y constante con los leprosos podían contraer la enfermedad, propagándose cada vez más la lepra y con ello aumentado el gasto nacional.

Otra forma de descongestionar los lazaretos y de impedir que se convirtieran en focos de infección fue apartar a los infantes que no padecían de lepra y confinarlos en asilos destinado exclusivamente para esto. Desde el 1 de mayo de 1907 mediante la Ley 14, el Gobierno Nacional se comprometió a sostener y educar a los infantes enfermos de lepra y a los hijos sanos de leprosos, por ser posibles portadores de la dolencia era indispensable tenerlos bajo control en lugares apartados de los lazaretos.

Para asegurar el cumplimiento pleno de esta disposición se ordenó instaurar en los lazaretos un servicio prenatal para vigilar la salud de las futuras madres durante el tiempo que durara el embarazo, convenciéndolas para que acudieran a la sala de maternidad en el momento del parto y exhortándolas a aceptar la separación voluntaria de sus hijos después del nacimiento. De forma paralela se decretó la obligación de denunciar ante el médico director del lazareto a toda mujer enferma o sana que se encontrara en estado de embarazo.

A las mujeres sanas provistas de cédula de residencia se les permitió abandonar esos lugares en un tiempo oportuno para que el parto se efectuara fuera de allí; si deseaban volver a la institución de aislamiento debían hacerlo sin sus hijos, pero si el padre del infante era un enfermo debían dar a luz dentro del lazareto y entregar al pequeño para ser internado en el respectivo asilo, según su género. El incumplimiento de esta medida fue causal suficiente para la cancelación de la cédula de residencia respectiva de la mujer sana y la perdida de la ración y de alojamiento de la persona enferma.

Una vez se producía el nacimiento se obligaba a los padres a bautizar a los infantes, sacramento indispensable para trasladarlos a las sala-cunas instauradas en los asilos, allí permanecían hasta la edad de dos años y medio, momento en el que eran llevados al jardín infantil ubicado en el mismo establecimiento, a los seis años empezaban a recibir la educación primaria y técnica que la Comunidad Salesiana ofrecía a los menores hasta los 18 años, edad en la que debían abandonar los asilos. En principio se estableció la edad de 15 años para decretar la "baja" o retiro de los asilos, pero para los años cuarenta ésta aumento tres años más (Resolución No 1207, octubre 28-1944). Al igual que en los asilos para niños enfermos de lepra ubicados dentro del lazareto, los asilos para quienes no lo eran, también estuvieron encomendados a la Comunidad Salesiana. Las condiciones que impuso el Gobierno para su funcionamiento fueron que se erigieran en lugares cuya distancia impidiera el trato fácil con los enfermos y la obligación de proporcionarles a los asilados la instrucción requerida para que en adelante pudieran subvenir por si mismos a sus necesidades, dejando claro la imposibilidad de volver a residir en los lazaretos luego de ser dados de baja (Ley 20, septiembre 26-1927).

Si bien, el Gobierno Nacional en su interés por medicalizar los lazaretos dispuso organizar médica y sanitariamente los asilos para niños y niñas sanos de lepra (Resolución No 60, junio 14-1933)' dicho proyecto, por lo menos en el lazareto de Contratación, no fue ejecutado por- 
que entre el personal a cargo de estos establecimientos no se encontraban profesionales de la salud y los que allí llegaban periódicamente a prestar sus servicios eran destinados a trabajar en el lazareto. Los médicos que visitaban los asilos lo hacían para detectar casos nuevos de lepra y llevarlos de regreso al lazareto junto con sus familiares cuando aún vivían, cuando no, eran asilados en el establecimiento respectivo de acuerdo a su sexo.

Los asilos más allá de proteger a los hijos sanos de enfermos de lepra del contagio y del estigma social que dificultaba su incorporación a la comunidad, como lo manifestaba el Gobierno Nacional (Decreto $\mathrm{N}^{\circ} 2980$, diciembre 26/1944), fueron preventorios, lugares para mantener controlados y vigilados a posibles portadores de la enfermedad, a la vez que fueron mecanismos útiles para descongestionar los lazaretos, ya que se esperaba que los menores al ser dados de baja nunca más regresaran a ellos, motivo por el que se les enseñaba un oficio para subsistir lejos de sus padres racionados.

Sin embargo, la resolución nacional que estipulaba las anteriores disposiciones, también concedía permiso a los enfermos de lepra para que continuaran teniendo a sus hijos sanos bajo su cuidado, para lo cual debían someterse a una serie de condiciones, entre ellas mantener a los menores completamente separados de los enfermos y ubicarlos en viviendas que cumplieran las normas básicas de sanidad (Resolución No 151, diciembre 7-1933). Teniendo en cuento la estrechez de los lazaretos y la carencia permanente de los servicios sanitarios y de infraestructuras adecuadas para vivir cómodamente, difícilmente se logró conseguir este permiso. Por consiguiente, los padres para evitar la separación de sus hijos debían esconderlos cuando las autoridades recorrían el lazareto buscado menores para ser asilados.
La severidad del sistema disciplinario instaurado dentro de los lazaretos conllevó a que el aislamiento de los enfermos en esos lugares se viera obstruido por la renuencia de algunos a ser forzosamente exiliados y cohibidos. Para este fin las autoridades gubernamentales igualmente debieron instaurar políticas motivacionales, entre ellas la decimonónica subvención y la prestación de servicios medico asistenciales. La "ración" era el dinero otorgado a los enfermos de lepra residentes en los lazaretos como ayuda para subsistir o como forma de pago por aceptar ser segregados; fue un recurso adoptado desde épocas anteriores, pero fue desde inicios del siglo XX cuando la administración central se comprometió a suministrarla de sus arcas y de manera constante. En la actualidad los leprosos continúan recibiendo este subsidio que equivale a un salario mínimo, aunque los lazaretos se abolieron oficialmente desde 1961 , los sujetos contagiados de esta enfermedad deben remitirse a Contratación, Agua de Dios o unos Centros especiales en Bogotá, para que les decreten la enfermedad, inicien tratamiento y puedan recibir este auxilio.

La falta de personal medico y la imposibilidad de encontrar curación científica a la enfermedad fue fundamentalmente la causa que provocó que la medicina practicada en los lazaretos estuviera encaminada a atender las necesidades generales de la población antes que tratar la lepra misma, al ser considerada como incurable (Obregón, 2002: p.72). De ahí que muchos leprosos fueron reacios a proscribirse en estos lugares, en donde sólo recibían consuelo para su alma porque el alivio a sus padecimientos físicos era casi imposible. Razones por las que la prestación de los servicios medico- asistenciales en los lazaretos fue una estrategia estatal para controlar la lepra, ayudar a quienes la padecían a poder sobrellevar las dolencias que los aquejaban y para 
incentivar a los enfermos renuentes a aislarse en los lazaretos.

No obstante, la falta de un mayor compromiso de algunos médicos que continuaban percibiendo la lepra con una mentalidad colonial, la ausencia de un mecanismo médico e higiénico realmente capaz de menguar los alcances de la enfermedad, sumado a la insuficiencia de fondos y la inexistencia de una estructura sanitaria para llevar a cabo las políticas propuestas, no permitieron durante la existencia oficial de los lazaretos concretar su conversión en instituciones médicas, tan sólo se dio el paso de establecimientos "hospitalarios" a instituciones de aislamiento, conformadas por varios establecimientos asistenciales como hospitales y asilos internos y externos para albergar a los niñas y niños sanos o enfermos hijos de leprosos; es decir, la conversión de los lazaretos en instituciones médicas no logró materializarse.

Con la ardua campaña antileprosa que se inició en los primeros años del siglo XX y se consolidó en las dos décadas siguientes, los enfermos de lepra además de padecer las terribles y dolorosas manifestaciones de la enfermedad, debieron soportar los señalamientos de la sociedad, quien los rechazaba y menospreciaba por padecer una enfermedad de la cual no sabían por qué ni cómo la habían contraído. Si bien, la lepra fue asimilada con el pecado, la pobreza e incivilización, ella no tuvo distinción social, política, cultural, económica y de género. Todos debieron sufrir el rechazo de la población y los padecimientos de la enfermedad, aunque las personas de mejor condición socio económica pudieron gozar de mayores beneficios dentro de los lazaretos, incluso se les asignó cargos administrativos.

La intolerancia, la represión y la indiferencia se constituyeron en la respuesta a la enfermedad por parte de la población ajena a ella, quienes esperaban que de un momento a otro, sin la compensación de un medicamento y/o de unas políticas higienistas y asistenciales acordes a las necesidades de los enfermos la lepra desapareciera del panorama nacional. Acontecimiento que efectivamente no sucedió, el proscribir a todos los enfermos de lepra en los diversos lazaretos no garantizaba la erradicación de la enfermedad, más aún cuando vivían los leprosos con personas sanas y en condiciones deficientes.

En 1930 los anteriores aspectos conllevaron al Gobierno Nacional a concluir, que no se justificaba gastar gran parte del presupuesto nacional destinado a garantizar la salud de la población, en una lucha infructuosa contra la lepra; aceptando planear una campaña que arrojara mayores resultados a un menor costo material y humano. La nueva campaña teóricamente redefinió al leproso como un enfermo al que había que tratar con medicamentos y medidas asistencialistas y no como un individuo peligroso que necesitaba ser controlado por métodos violentos y represivos.

Propósito que se pretendió efectuar mediante la conversión de los "hospitales" en sanatorios entendidos como establecimientos para la estancia transitoria de los enfermos de lepra, cuya función principal era buscar la curabilidad de los leprosos. Medida apoyada en el descubrimiento de científicos alemanes y estadounidenses sobre la efectividad de los derivados sulfonicos para sanar la enfermedad en algunos leprosos. Aún así, en Colombia para 1949 por el costo excesivo de las sulfotas y a la dificultad para conseguirlas en suficiente cantidad, el Chaulmugra todavía ocupaba un lugar predominante en el tratamiento de la lepra.

Con la reorientación de la campaña antileprosa declinaron paulatinamente las drásticas medidas constituidas para contener esa enfermedad, modificándose la forma en que debía realizarse el aislamiento. Es así, como en 1929 el Estado y la comunidad médica colombiana contemplaron la 
posibilidad de liberar enfermos después de períodos de observación entre los seis y doce meses, durante los cuales se sometían a diversos exámenes y prácticas para establecer si el bacilo de Hansen había desaparecido de sus cuerpos y poder ser decretados como personas no peligrosas para vivir en sociedad, llamados luego "curados sociales" (Resolución No 34, mayo 27-1929).

Para 1932 por el incumplimiento a la presente disposición, nuevamente se decretó la liberación de los enfermos, replanteándose la forma en que debía realizarse. Se estableció que sólo los casos contagiosos debían aislarse por ser altamente peligrosos para la sociedad, mientras que los individuos que no presentaban el bacilo de Hansen al momento de ser examinados bacteriológicamente, así la enfermedad hubiese dejado en ellos consecuencias graves como discapacidades o deformaciones, debían dejarse en libertad pero sometidos a la vigilancia de las autoridades (Ley 32, noviembre 18 -1932).

De igual manera, en 1933 se concedió permiso a los enfermos de efectuar su aislamiento en lugares distintos a los lazaretos. Fue así como se planteó que todos los enfermos infectantes, es decir, aquellos que presentaran lesiones abiertas y signos bacteriológicos positivos debían ser proscriptos, procedimiento que podía ejecutarse en los lazaretos o a domicilio. Incluso se contempló la posibilidad que éste se hiciera en salones especiales ubicados en los hospitales oficiales, lo cual no sucedió porque los hospitales del país no contaban con el personal, la infraestructura y demás medios requeridos para la adecuación de un lugar destinado a la atención y sostenimiento de los leprosos, sumado a la aversión de los enfermos endémicos y los pacientes ambulantes a convivir de cerca con los leprosos.

El aislamiento a domicilio se condicionó a la posibilidad que tenían las autoridades sanitarias de vigilar constantemente a los enfermos y a la posibilidad que los leprosos tuvieran de contar con recursos suficientes para hacer efectiva esa medida. Los enfermos debían permanecer siempre en su domicilio, no visitar ni hacer uso de establecimientos públicos, no compartir sus utensilios o ropaje, no ejercer profesión u oficio que tuviera un contacto directo o indirecto con las personas exentas de la enfermedad, someterse a los tratamientos establecidos y a exámenes periódicos (Resolución $\mathrm{N}^{\circ}$ 60, mayo 19-1933) .

Considerando las estrictas condiciones para conceder el aislamiento a domicilio era de esperarse que pocas personas hicieran uso de él, prefiriendo gozar de las "libertades" otorgadas en los lazaretos, ya que dentro de esas instituciones convivían entre iguales, con personas que compartían la misma enfermedad y el mismo ostracismo, y les eran devueltos los derechos civiles que por su condición fuera de los lazaretos les eran negados, el único derecho al que no tenían acceso los enfermos era al de elegir y ser elegido para ocupar algún cargo público, derecho que les devolvió hasta la eliminación de los lazaretos en 1961, momento en el que se derogó la condición que le daba sentido a su funcionamiento como era el aislamiento obligatorio. Con su abolición declinó la estructura institucional que segregaba, proscribía y coartaba a los enfermos de lepra, aspectos que enmarcaron su decadencia institucional.

Al realizar el estudio interno del lazareto de Contratación se pudo establecer que las políticas nacionales enfocadas a la represión de los enfermos tuvieron un acatamiento inmediato, pero no sucedió lo mismo con aquellas que buscaban el beneficio de los enfermos y el progreso material de los lazaretos, como era la de hacer de ellos instituciones médicas. Aunque esa conversión institucional fue la panacea de la moderna campaña sanitaria adelantada por el Gobierno Nacional para 
combatir la lepra desde 1931. El lazareto Colombiano fue hasta su eliminación oficial una institución de aislamiento.

A pesar que paulatinamente las ciencias médicas penetraron a los lazaretos, no se puede decir que su abolición como lo presentaron las autoridades gubernamentales y médicas se debió a su transformación, esto fue la convergencia de diversos factores, entre ellos el hallazgo de medicamentos con mayores capacidades de controlar la lepra, la planeación de una lucha contra la enfermedad por fuera de los lazaretos mediante la creación de campañas preventivas y la ampliación de la asistencia hospitalaria, y la modernización de la estructura sanitaria del país y de la concepción de salud pública que se estaba adoptando, jalonada amplia e intensamente por países como los Estados Unidos y organizaciones sanitarias internacionales. Asimismo, su eliminación fue producto del interés desmesurado del Gobierno Nacional por disminuir los costos de una batalla emprendida contra una enfermedad sobre la que pesaban más los escrúpulos y las creencias coloniales que su verdadera magnitud o peligrosidad.

En 1961 la eliminación oficial del lazareto de Contratación y de Agua de Dios, puesto que el de Caño de Loro fue abolido décadas antes, no significó la erradicación total de la lepra. Su control con acción bactericida fue transcendental en la lucha con una enfermedad que no mata pero deforma e incapacita a quien la padece. Sin embargo, en el siglo XXI continúan apareciendo casos de lepra en estado avanzado, el olvido o desconocimiento de la enfermedad ha dificultado su diagnóstico temprano; el recorte del presupuesto necesario para combatirla mediante campañas preventivas y tratamientos farmacéuticos, y la priorización de otras enfermedades de origen reciente, han generado que el sistema de salud pública colombiano no haya podido desaparecer del panorama nacional a una enferme- dad medicalizada hace varias décadas y propia de países con menor grado de desarrollo.

\section{Conclusiones}

Las nefastas e irreversibles consecuencias que dejaba la lepra en las personas que la padecía, la dificultad para dilucidar su modo de trasmisión y de contenerla mediante tratamientos médicos, conllevó al Gobierno Nacional a catalogarla como una calamidad pública y a responsabilizarse de su control a través de una enérgica campaña fundada en la persecución y represión de los enfermos, obligándolos a proscribirse en los lazaretos, lugares que buscaron adecuarse y modificarse para hacer más efectivas las políticas contra la lepra y más llevadero la permanencia de los enfermos dentro de éstos.

En consecuencia, se pudo establecer que los lazaretos en ese país sufrieron oficialmente dos transformaciones, desde comienzos del siglo XX pasaron de establecimientos hospitalarios de beneficencia a instituciones de aislamiento y posteriormente a instituciones médicas, proceso que se adelantó enfáticamente a partir de 1940. No obstante, en la práctica sólo se vio manifiesta la primera transformación, pese a que se produjeron notables cambios en las drásticas políticas utilizadas para disminuir los índices de lepra en el país, percibiéndose su inclinación a adoptar un carácter médico-hospitalario, estos aspectos no pueden ser utilizados para plantear que los lazaretos en su práctica fueron instituciones médicas.

\section{Referencias}

ACTOS LEGISLATIVOS Y LEYES DE COLOMBIA. (19311961).

DIARIO OFICIAL. (1931-1961).

FOUCAULT, M. (1976). Vigilar y Castigar: Nacimiento de la Prisión. Francia: Siglo XXI.

GACETA DE SANTANDER. (1931-1961).

LEGISLACIÓN COLOMBIANA SOBRE LA LEPRA. (1937). COLOMBIA: LA LIT.

OBREGÓN, D. (2002). Batallas contra la lepra: Estado, medicina y ciencia en Colombia. Colombia: Banco de la República- EAFIT.

ORDENANZAS DE SANTANDER. (1931-1961). 
PÉREZ, L. (2004). Regenerar la Muerte: la política sanitaria en el Estado Soberano de Santander. Instituciones de beneficencia, organizaciones de caridad y establecimientos de salubridad (lazaretos, hospitales y cementerios), 1857-1886. Tesis de maestría no publicada, Universidad Industrial de Santander, Bucaramanga, Colombia.

RABAGLIATI, E. (1899). El doctor Hansen y los lazaretos en Colombia: Informe a la junta de la sociedad de San Lázaro. Colombia: Escuela tipográfica salesiana.

REGLAMENTO DE LOS LAZARETOS DE LA REPÚBLICA. (1914). COLOMBIA: IMPRENTA NACIONAL. 